\title{
Web-based admission system for advanced level, private schools: case of Kilimanjaro region, Tanzania
}

\author{
Mwapashua H. Fujo ${ }^{1 *}$ and Mussa Ally Dida ${ }^{2}$ \\ Master's Scholar, School of Computational and Communication Science and Engineering, Nelson Mandela African \\ Institution of Science and Technology, Arusha, Tanzania ${ }^{1}$ \\ Lecturer, School of Computational and Communication Science and Engineering, Nelson Mandela African \\ Institution of Science and Technology, Arusha, Tanzania ${ }^{2}$
}

\section{(C2018 ACCENTS}

\begin{abstract}
This paper takes a look at the various challenges facing admission procedures for advanced level (A-Level) private schools case of Kilimanjaro region in Tanzania. Questionnaires were distributed to gather data from potential users of a new proposed admission system; namely: parents, A-Level students and school staffs, to find out procedures likewise the challenges being faced in the course of carrying out admission procedures and their level of satisfaction of the existing admission system. Thereafter, the analysis of the survey results confirms and quantify that $93.5 \%$ of admissions into ALevel private schools are performed manually by ink and paper. This manual system has its major problems which include difficulty in locating an appropriate school and subjects an applicant can get admissions, wastage of time, loss of forms and mutilation of forms throughout the entire method for admission. Consequently, this paper reports on an ongoing research work to design and implement a Tanzania central processing admission system (TCPAS) that has the outstanding changes towards maintenance of admission costs, control forgery over entry qualifications, encourage the use of paperless admission, ability to reach several geographically scattered candidates and enhancing centralized data handling capability.
\end{abstract}

\section{Keywords}

Admission system, A-Level private schools, CSEE, NECTA, TCPAS, Web portal.

\section{Introduction}

Globally, millions of students seek for admission during the last year of their pre-college education to graduate schools, colleges or universities. Of concern is that, the admission approaches differ from country to country, and typically from institution to institution [1].

In developed countries (e.g. the United Kingdom, France, etc.), the admission into tertiary institutions, universities, colleges, and schools are centralized. In the sense that, colleges or schools receive applications through a web portal, and applicants are not required to collect and fill the physical forms; rather they would only visit the admission website of a particular school or college, and all eligibility criteria are mentioned on the site [2]. Such admission systems include common application in the United States of America. Joint University Programmed Admission System in Hong Kong (JUPAS).

*Author for correspondence
University College Admission System in China (CUCAS), and the Universities and Colleges Admission Service (UCAS) in the United Kingdom [3]. Such admission systems adopted as a means of saving resources time and money to both applicants and colleges, and harmonizes the turnaround time during the admission process [4]. However, there were unsolved difficulties like, a way to handle multiple admissions and save admission vacancies, centralized data handling capability, ability to achieve many geographically scattered candidates, and the way to make sure management over forgery of entry certificates throughout the application [5].

Additionally, in China, like in most developed countries, there are government boards or agencies which harmonize the admission process by offering admission exams to applicants. This has caused students to invest a lot of time and effort to prepare for such exams. However, candidates perform differently on these exams, which do not necessarily reflect their real abilities. As a result, the colleges might end up enrolling unqualified candidates. Therefore, this makes the application procedure very 
tiresome, being costly, less fair and even less considerate [3].

A case in point, in developing countries, it is desirable to have fair and transparent student admissions system in both public and private universities, colleges and schools. Same challenges like scarce resources, underdevelopment, gender inequality and the quest after advancement in science and technology, as causal factors; has led to the requirement to use a fair and transparent method of selection for admission to both ordinary, advanced and tertiary institutions, to make sure there is equal distribution of available admission vacancies or spaces for candidates aspiring to join Higher Educational Institutions (HEIs) as well as precolleges institutions [6].

For instance, in Nigeria the researchers have been making every effort to develop intelligent decision support systems that may facilitate in university admission procedures [7]. But currently the admission approach into both pre-colleges and tertiary institutions are decentralized. In the sense that, every university, college and school has a power to make decisions on their admission independently [8]. Such admission approach characterized by multiple admissions, uniformity in the admission processes, being costly, inconsistency, inaccuracy, difficulties in setting admission standards and following admission procedures. As a result, one candidate can receive offers of admission from more than one institution or college, and admitted to more than one college and abandon some of the vacancies. For this reason, most of admission seeker for precollege and university education in Nigeria, show desperation in their efforts to achieve admissions into the highly limited available admission vacancies [9].

Parallel to the developing countries, admission process into public and private universities in Uganda is done by two systems: A Joint Admissions Board (JAB) that is governed by the government for public universities and direct admissions for private universities. This board JAB periodically sits to a make decision of candidate requests and select qualified applicants whom it assigns to different public universities and different disciplines. However, during such admission procedure, there is a lack of fairness and transparency. For private universities and university college applicants physically collect the application forms themselves, which in turns cost in terms of time and money.
In contrast, in Tanzania the establishment of webbased admission system is one of the greatest innovations for monitoring and controlling quality for admission into technical and tertiary education. Additionally, has become potential for evaluating the applicant's quality, standard of entry requirements, and control the widening access to higher educational institutions [10]. Thus, the government of Tanzania in 2010 control the operations of admission into higher and technical educational institutions through a Centralized Admission System (CAS), which was under the supervision of two regulatory boards named National Council for Technical Education (NACTE) in collaboration with the Tanzania Commission for Universities (TCU) [11]. In 2017 the government of Tanzania revoked the admission process through TCU. Apparently, each institution can process admission creatindependently; thereafter all institutions are required to upload the selected candidates into the system for TCU to approve, to make sure that all selected candidates approved by their institutions satisfy TCU and NACTE minimum entry requirements for each programme [12].

Furthermore, Tanzania is one among the few countries that follows a 7-4-2-3 system of education. That is; primary schooling takes seven years, followed by four years of Ordinary Level (O-Level) education, two years of Advanced Level (A-Level), and three years of the first degree for higher educational institutions [13]. Reports from the ministry of education in Tanzania in 2017 indicate that, over $35 \%$ of candidates join into technical and higher educational institutions for each academic year are from A-Level private schools [13]. Despite of contribution of A-Level private schools into higher level learning institutions and the existence of these two systems for admission (TCU and NACTE), but to date the enrolment of students in A-Level private schools is done manually by ink and papers which is difficult to perform, inconsistency, less accurate and very difficult to complete the entire admission process. Such manual admission systems are considered unfair and not transparent [14]. In dealing with these challenges a centralized web-based solution has been proposed, namely; Tanzania Central Processing Admission System (TCPAS), to resolve the identified admission challenges. Therefore, this paper reports on an ongoing research work to design and implement a TCPAS software tool for A-Level education in Tanzania, case of private schools in Kilimanjaro region. 
The rest of the paper is organized as follows: Section two presents a collection of tools and techniques that are guiding the reported study. Section three presents the software requirements and design consideration of the proposed software solution. Section four present's survey data and discussion on how the designed software solution has potential to mitigate the challenges facing current admission procedures into A-Level education in Tanzania, case of private schools in Kilimanjaro region. Section five has a conclusion and recommendation.

\section{Materials and methods}

Kilimanjaro as one among the five administrative regions that has a high number of A-Level private schools compared to other regions in Tanzania, was selected as a study area for the reported study. This is due to colonialism impacts, demographic factors and religious activities. Thus, $64 \%$ of A-Level private schools in Kilimanjaro region are owned by religious institutions exclusively. Additionally, most of these schools are well invested in ICTs infrastructures (that is; computers and internet connectivity are already integrated as a medium of instruction) [14]. Kilimanjaro has a population of $1,640,087$. Also, it is bordered by Tanga region, Arusha region, Manyara region and with Kenya in the eastern zone, as shown in Figure 1 [15].

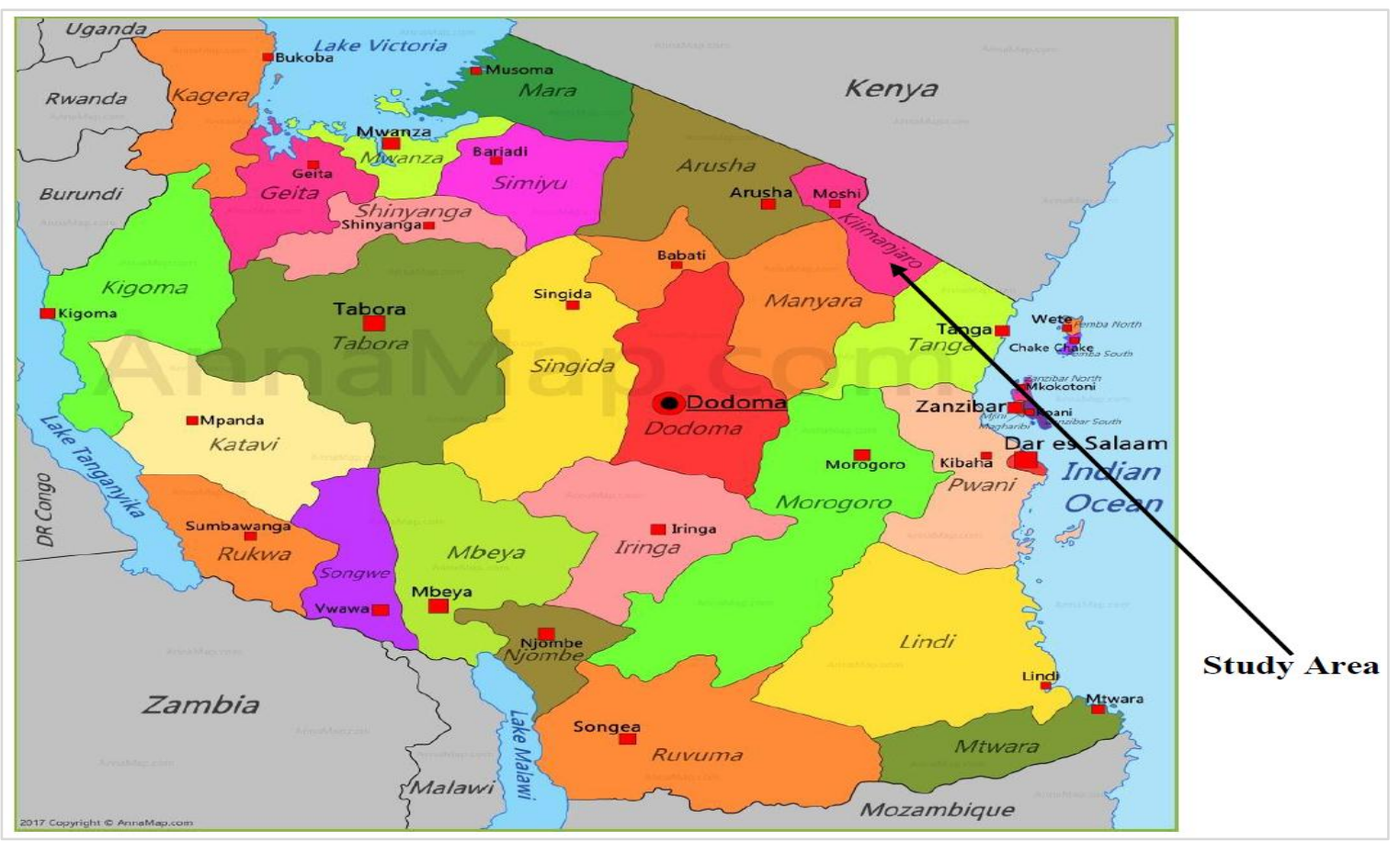

Figure 1 A map of Tanzania showing the Kilimanjaro region as a study area

This research was adopted a case study approach. The 150 voluntary respondents or participants were selected as a study sample, and clustered into three groups, namely: parents, A-Level students and school staffs. During the month of February 2018, At the beginning of week 1 to week 4 , questionnaires were distributed to collect data from the households, in which 25 houses which were expected to have at least one candidate were selected; followed by school staffs: in which 25 school admissions officers were selected. At the end of the week 3, the last group of students was considered; in which 100 A-Level students were selected randomly from the study sample. For this study, the distributed survey questionnaires were administered by using the Open Data Kit (ODK) software, and it had both hardcopy and softcopy questions. During the end of week 4 the collected statistical data were analyzed and virtualized by using SPSS software. Thereafter, we started to extract the software requirements and design consideration of the proposed software solution TCPAS based on the collected and analyzed survey data.

A flowchart in Figure 2, presents workflow or processes that illustrate the procedures used to guide 
this study. Flowchart was used as results of, it's terribly representative and precise throughout analysis, design and documentation of the research findings. In Figure 2, an arrowhead or a flow line: shows the process order of operation; means a line returning from one symbol and pointing at another. A
Diamond box: represents a decision; means a condition, and its operation is mainly being true or false. And the rectangle presents a process; means a set of operation that should be performed to complete the overall milestone in this study.

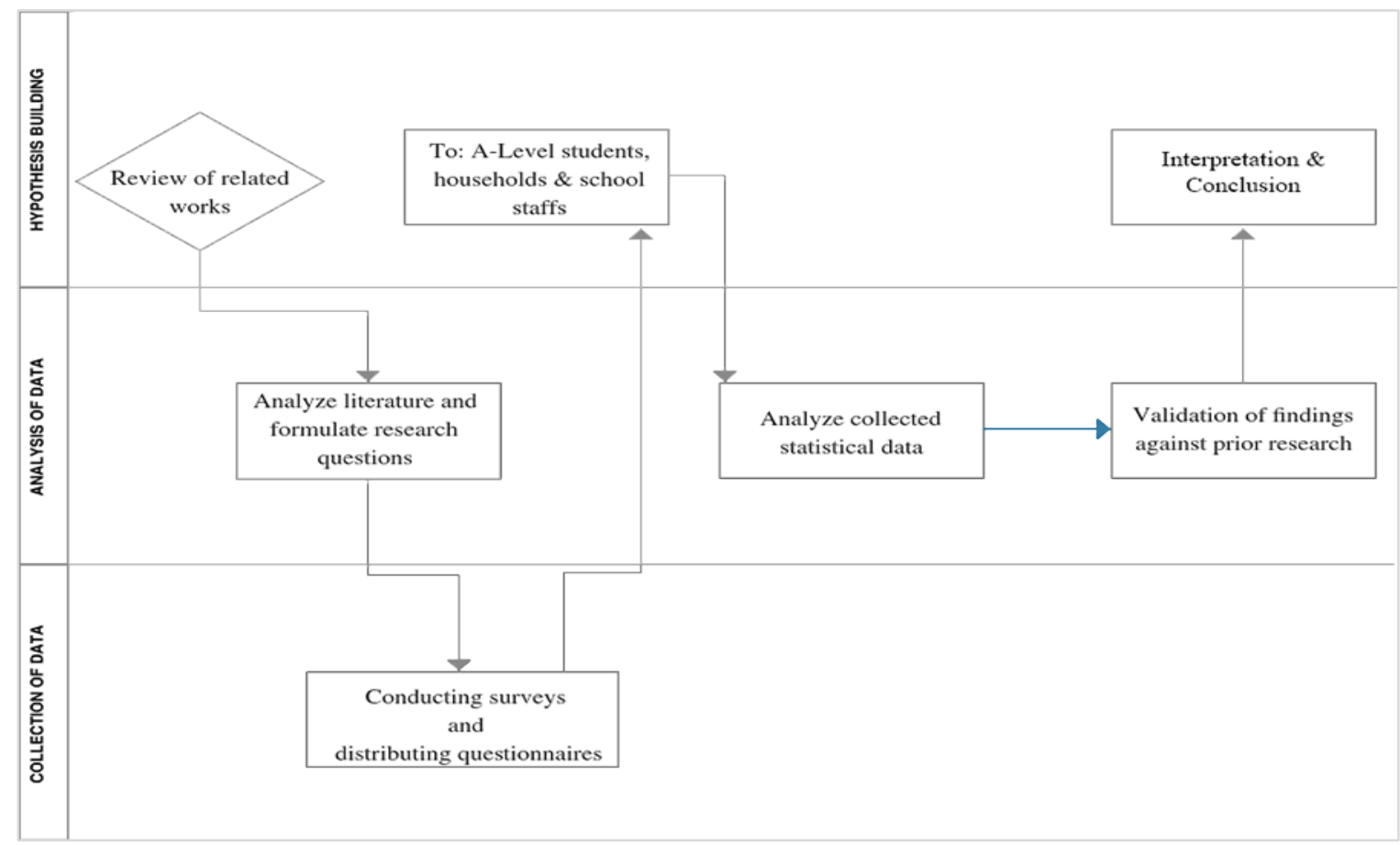

Figure 2 Presents a procedural flowchart of the methodology

\section{Requirements specification and design consideration}

The main objective of this study is to develop a TCPAS for A-Level private schools, to replace the existing manual admission system. To achieve the main objective of the study, an ideal TCPAS software solution should meet the following user requirements: - The software must provide a means of representing, accessing and handling the admission information/data in a centralized way.

The software should allow applicants to apply directly to schools, and then the system should make decisions based on criteria for admitting students specific to that particular school on its own.

The software should allow schools to set admission criteria. Also, should provide an interface or panel for applicants to file their applications.

The software must provide a means for controlling and managing multiple admissions and saving admission vacancies. The applicants should be given a slot/limit number of admissions. As well, the admission procedure should support two-way interaction (to-and-fro) approaches.

The software should allow applicants to perform the applications through a web portal and answer all the required queries by using mobile phone messages. Also, it should be compatible with both web-mobile platforms, and integrated with unstructured supplementary service data (USSD) for mobile messages technology.

The software must provide a means of providing an equitable access for applicants scattered geographically by using their computers and smartphones. The software should make sure that, printed or scanned copies of applicants' entry certificates will no longer be required during the admission process. An applicant should be required to submit the index number of their Certificates of Secondary Education Examination (CSEE). Also, all 
verification of applicants' entry certificates should be done through an application programming interface (API) to the National Examinations Council of Tanzania (NECTA) database which must be integrated within the TCPAS. The software should allow all payments for admission processing to be made electronically through mobile (Tigo-Pesa, Mpesa, etc.) or banking financial services. The software should set a mechanism that will provide weekly or rapid notifications on the progress status of admission processing. Also, it should permit each applicant to provide valid Email or phone number for notification.

The software should allow an applicant to make multiple applications for admission at affordable prices; International Telecommunication Union (ITU) recommends a monthly affordability of less than $5 \%$ of monthly income [16]. In the case of Tanzania, basic salary per month is US\$78. The $5 \%$ of this amount is approximately US\$3.9, which translates into US\$0.13 per day. It is considered that the admission processing fees per applicant should not exceed this amount.

\section{Results and discussion}

This section is dedicated to showing how the survey results confirm and quantify the challenges for current admission procedures into A-Level private schools; and shows how the new designed software solution TCPAS will meet the requirements of an ideal proposed admission system for A-Level private schools. The first part shows the framework of the designed web-based solution, then followed by analysis and discussion of survey results.

A framework in Figure 3, shows a diagrammatic representation of a proposed software solution model to a given admission problem. Thereby used to analyze the user necessities, design the model of the system, and managing a designed software system in numerous fields; means from requirements analysis up to the system testing and maintenance. Step 1, 2 and 3: shows on how applicants will be capable of sending and receiving admission feedback through computer or smartphone via an internet connection. Step 4 shows how applicant requests are going to be stored in a centralized database. Step 6 shows how schools organized in zones, for this case it is straightforward for applicant to locate or spot an appropriate school and subjects that he/she can get admission. Lastly, with the assistance of internet connection in step 5, all schools will be able to receive applicant's requests and send acknowledgement feedback of acceptance or rejection back to the applicants.

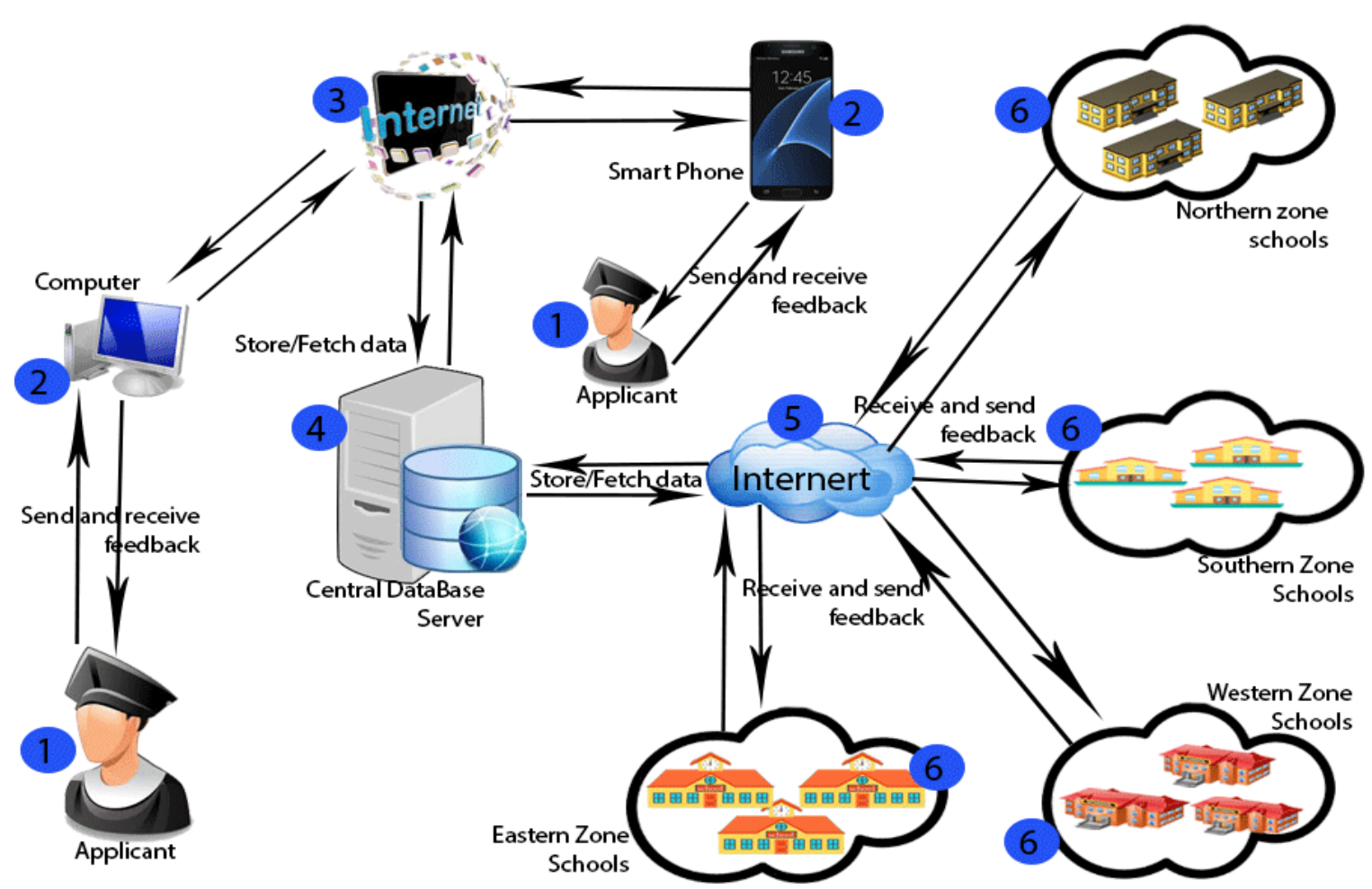

Figure 3 Framework of the designed software tool (TCPAS) 
4.1How to reach many geographically scattered applicants?

During the analysis of survey results in Table 1, the study confirms that still there is less awareness of the existence of A-Level private schools in Tanzania. Also, this study quantifies that, about $37 \%$ of applicants in Kilimanjaro Region-Tanzania are from outside the region of Kilimanjaro, but the most of them face challenges on awareness concerning the existence of A-Level private schools. For this reason, most of the A-Level private schools in Tanzania use regional media like radio and television to provide awareness to applicants scattered geographically, which in turn cost money, as well as an airtime slot for advertisement. Of concern is that, these media adverts don't seem to be scattered countrywide, therefore access to geographically scattered candidates stay to be a major challenge.

Table 1 Applicants' residence in relation to school location in Kilimanjaro region

\begin{tabular}{lll}
\hline Variables & Frequency & Percentage \\
\hline Applicants from Kilimanjaro region & 95 & 63 \\
\hline Applicants from outside Kilimanjaro regions & 55 & 37 \\
\hline Total & $\mathbf{1 5 0}$ & $\mathbf{1 0 0}$ \\
\hline
\end{tabular}

To mitigate this challenge, the new designed software solution TCPAS will provide direct open access for candidates to send application requests for admission to schools, through their computers and smartphones in their geographical position. To achieve this, TCPAS provides a direct portal to both A-Level private schools, and applicants scattered geographically via a web browser and through (http://www.tcpas.ac.tz). For this approach, the TCPAS achieves the requirement of A-Level private schools reaching many candidates scattered geographically.

The user interface in Figure 4 shows a designed web portal to A-Level private schools and applicants scattered geographically. Through this API users are able to access admission contents concerning A-Level private schools in Tanzania, through a web link, via computer or smartphone.

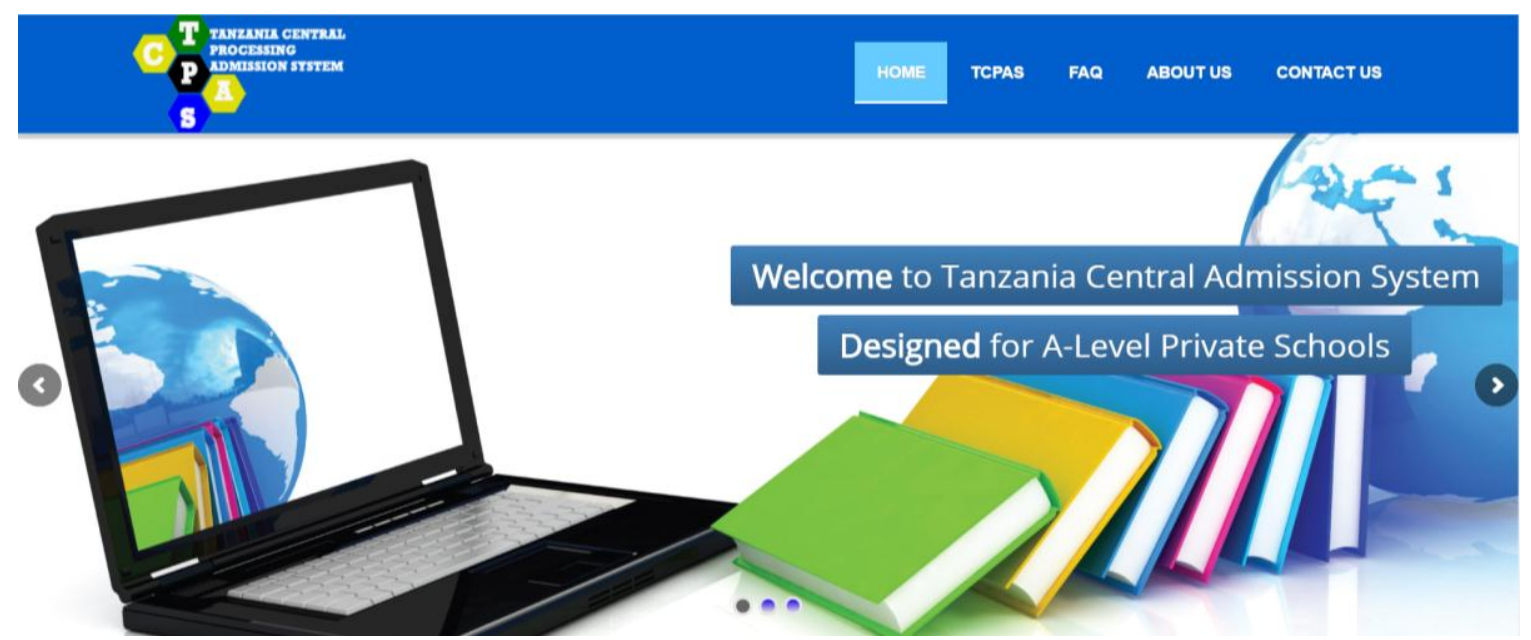

Figure 4 Web-portal interface for the TCPAS (http://www.tcpas.ac.tz)

\subsection{How to encourage centralized data handling capability?}

Through the analysis of survey results in Figure 5, it was revealed that the admission procedures in ALevel private schools are totally decentralized. These admission approaches, left school with the mandate to process the admissions requests on their own. In this case, it was further realized that most of A-Level private schools in Kilimanjaro region take a month $(30 \%)$ or more than a month $(20 \%)$ to process the applications, and to send feedback of acceptance or rejection back to the applicants. Therefore, these admission procedures cause further delay in commencing new academic years and makes it harder for applicants to make decisions about where, when and which subjects they can fit in. 
International Journal of Advanced Technology and Engineering Exploration, Vol 5(47)

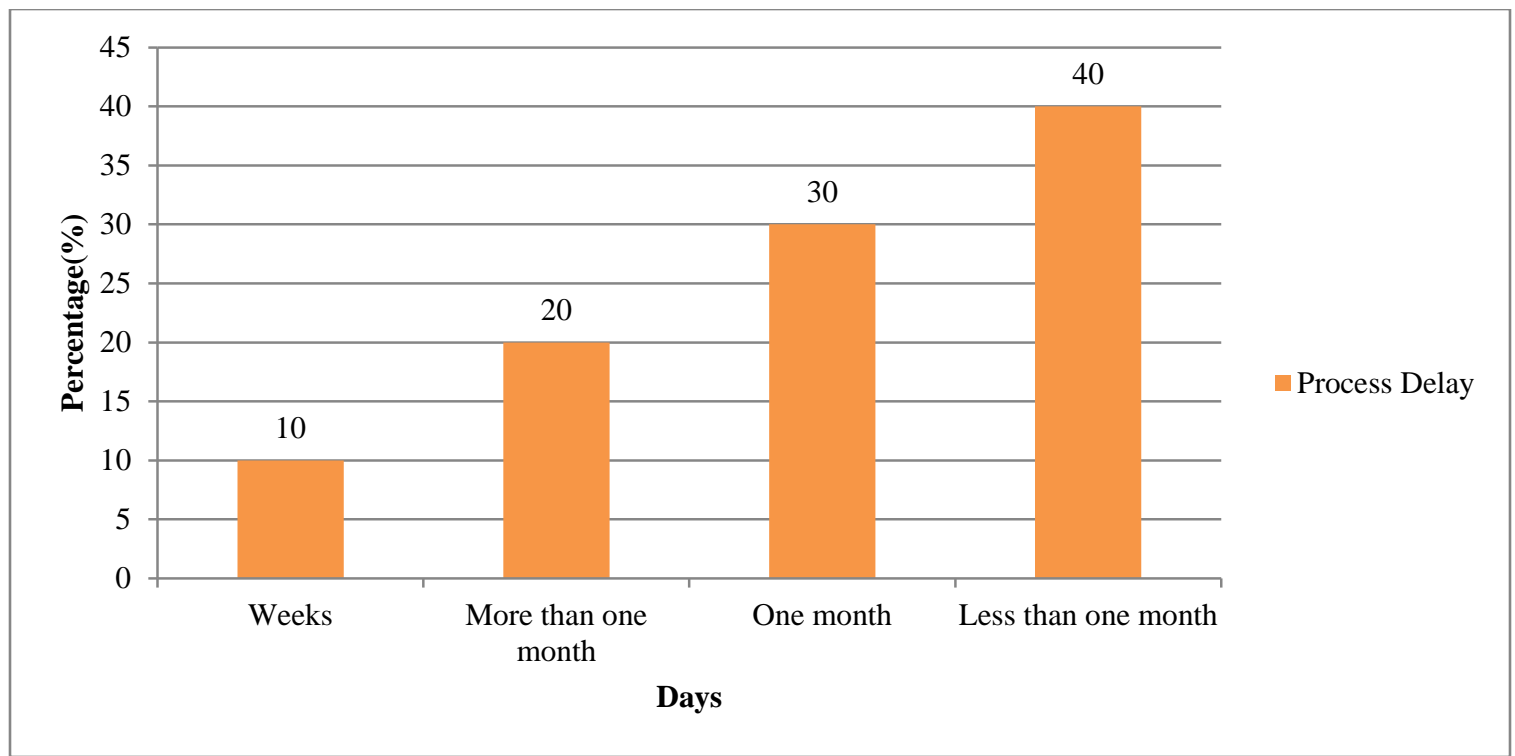

Figure 5 Delay caused by manual admission procedures into A-Level private schools in Tanzania

To mitigate this challenge, the new designed software solution TCPAS will retrieve process and handles the admission data in a centralized way. Also TCPAS will provide detailed information about schools registered in the system, including school name, location or physical address, school-position in the national exams, school services and school admission vacancies. For this reason, the TCPAS achieves the requirement of A-Level private schools to handle admission data in a centralized database, and make easy way in which applicants can spot all possible ALevel private schools and subjects that they can get admissions.
The user interface in Figure 6, presents list of ALevel private schools organized in zones. The left panel presents access links of all regions in Tanzania that have at least one A-Level private schools. Then, within the middle panel, it includes navigation tabs that contain a list of schools delineate by school logo, offered admission vacancy, link for applying and also the link for applicant to look at additional details concerning school services, and acquire admission supported his/her preferences.
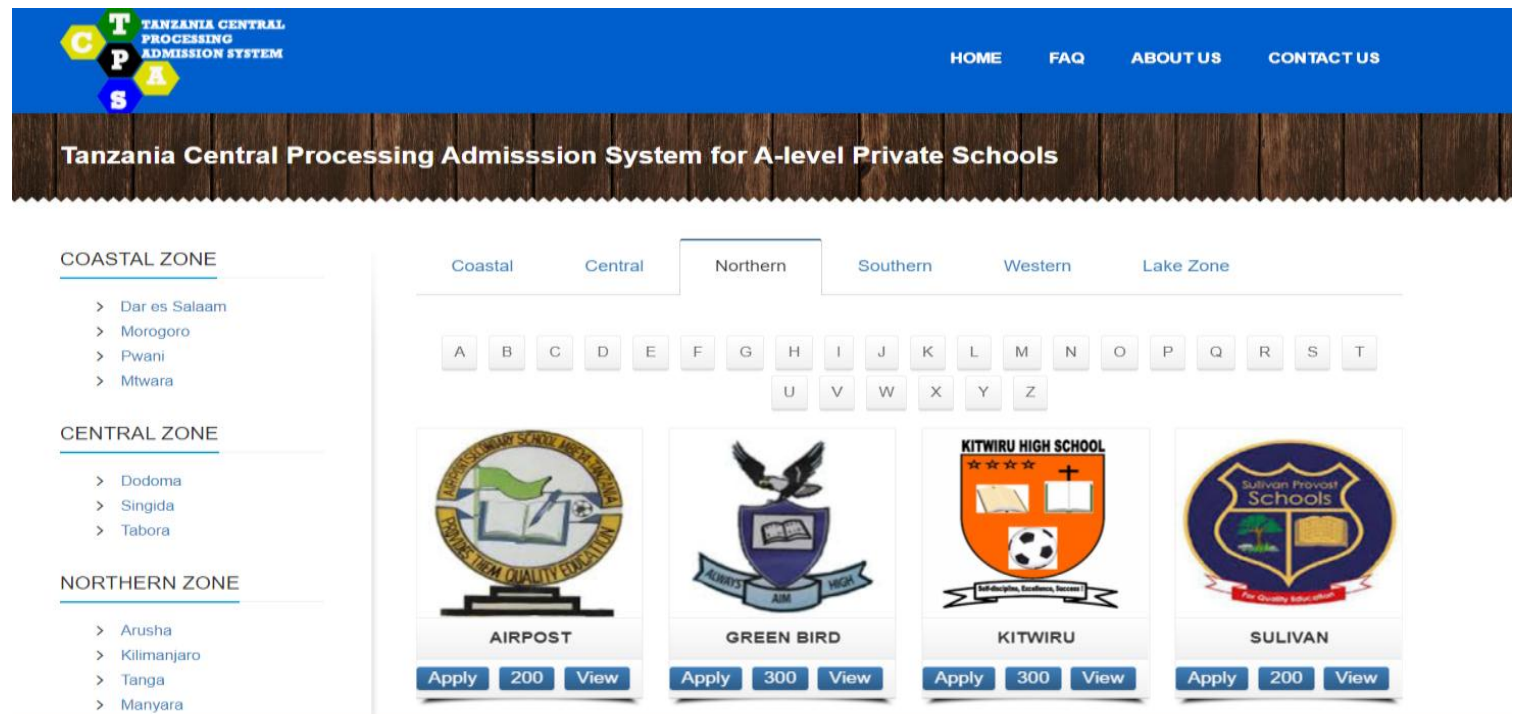

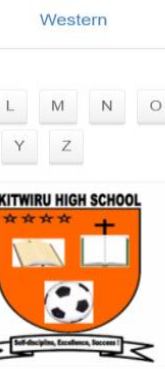

KITWIRU

Apply 300 View
Lake Zone

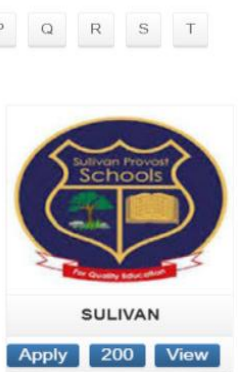

Figure 6 Sample list of A-Level private schools in Tanzania grouped in zones 
Fujo and Dida

4.3How to ensure control over forgery of certificates during application?

From the analysis of survey results in Figure 7, the survey data show that $87 \%$ of A-Level private schools in Kilimanjaro region face some difficulties during verification of certificates, due to lack of education regulatory board to evaluate the applicants' quality before being admitted into A-Level private schools. In such a process, there is a lack of fairness and transparency during the admission processes. Notable is that, only $13 \%$ of A-Level private schools in Kilimanjaro region use their own education boards to manage, control and maintain fairness and transparent throughout the process of admissions.

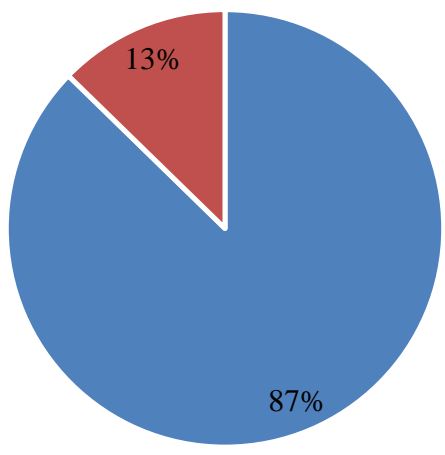

- A-Level private schools without regulatory boards - A-Level private schools having regulatory boards

Figure 7 Availability and applicability of regulatory board for current admission procedures into A-Level private schools in Tanzania

To mitigate this challenge, in the designed software solution TCPA) candidates will only be required to provide the index number for their CSEE. In such a process, no printed or scanned copies of certificates will be required. Additionally, all processing of entry certificates will be performed by the system automatically through an API, that query applicants' results from NECTA database integrated within the TCPAS. For this approach, the TCPAS achieves the requirement of A-Level private schools, that is; to ensure there is management and control of forgery of entry certificates during the application process.

Figure 8, shows how the designed system will fetch applicant details (including personal information and examination results) from NECTA database integrated within the TCPAS. A second user input field in Figure 8, also presents how an applicant is going to be allowed to provide an email address, so as to receive verification link and be able to confirm that he/she is a legible candidate.

\section{Verification Phase:}

\section{Verification Info:}

\section{Index (Example: S.3427/0155)}

\section{E-mail (Example:fujoprof@gmail.com)}

\section{0}

Figure 8 Interface for verification of applicant details 
4.4How to reduce the cost of admission process In this study it was confirmed from the survey results in Figure 9 that, 35\% of applicants registered for each academic year in higher educational institutions are from A-Level private schools. But, still $94 \%$ of admission procedures in A-Level private schools are performed manually. Such admission approaches consume much effort and time, up to 3 months, and in the average costs of US\$22 for each applicant throughout the whole processes of admission. This makes the application procedures to be expensive and annoying.

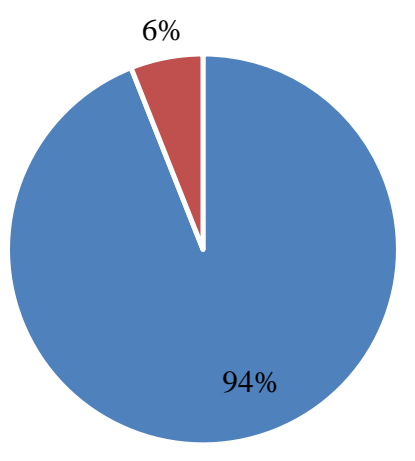

- Admission procedures handled manually

- Admission procedures handled electronically

Figure 9 Shows how current admission procedures in A-Level private schools are handled

Therefore, within the new designed software solution (TCPAS) there is a remarkable change regarding to the cost of admission. Applicants are permitted to pay an equivalent of US\$2.6 as an application fee, and capable of doing multiple admissions based on his/her choice. Alternatively, all payment methods will be performed electronically through mobile (AirtelMoney, Z-Pesa, Tigo-Pesa, Mpesa, etc.) or banking financial services. By doing so, the TCPAS achieves the needs of applicants, because suggest admission fee is affordable and not exceeded the recommended amount by the ITU that is; US\$3.9.

The user interface in Figure 10, shows a panel where an applicant is going to provide a voucher number, after he/she pay for admission through mobile payments (such as: Airtel-Money, Z-Pesa, Tigo-Pesa, Mpesa, etc.) or banking financial services, and issued voucher number to his/her mobile phone. After this payment verification, the applicant will be allowed to proceed to the next stage for admission processes, as shown in Figure 11 and 12.

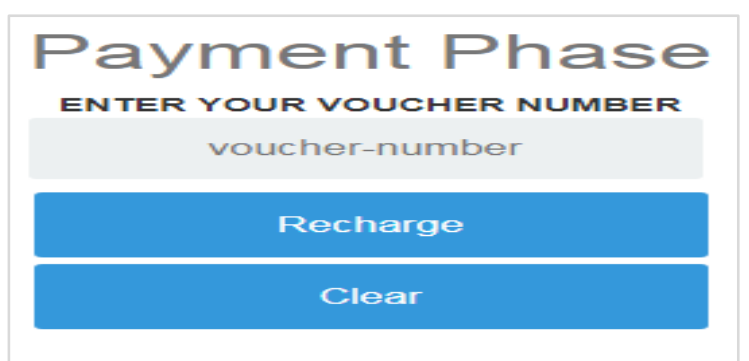

Figure 10 Presents interface for applicants to pay for admission application

\subsection{How to save admission vacancies?}

Survey data in Table 2 confirm that, one of the major challenges for admission procedures into A-Level private schools in Tanzania, is in the absence of education boards or centralized system to manage, control and monitor the admissions procedure. Thus, $78 \%$ of A-Level private schools in Kilimanjaro region deliver a number of candidates that are below their expectations. This is often because of the undeniable fact that, applicant physically collects forms from various schools and lodges multiple applications and abandon a number of the vacancies. As a result, some applicants will not be able to apply to several schools, and others would be admitted to more than one school. 
Fujo and Dida

Table 2 Delivering candidates' expectation rate for A-Level private schools

\begin{tabular}{lll}
\hline Variables & Frequency & Percentage \\
\hline A-Level private schools that deliver a number of candidates that are below their expectations & 117 & 78 \\
\hline A-Level private schools that deliver a number of candidates that are within/above their expectations & 33 & 22 \\
\hline Total & $\mathbf{1 5 0}$ & $\mathbf{1 0 0}$ \\
\hline
\end{tabular}

Therefore, the new designed software solution TCPAS comes out with an ideal approach with aim to handle multiple admissions and save admission spaces. Thus, the new designed solution uses bidirectional (to and fro) approaches in the sense that: phase one, an applicant will be allowed to perform multiple admission requests; and later on may receive multiple acknowledgements from more than one school. Eventually, in phase two, an applicant will be permitted to acknowledge and send acceptance solely to one school, thereby leaving vacancies to others. For this approach, TCPAS attain the need of handling multiple admissions and saving admission vacancies. The user interface in Figure 11, shows an instance where an applicant made multiple applications, and still waiting for acknowledgement feedback from the respective schools. Parallel to that, Figure 12 shows on how an applicant is permitted to acknowledge and send acceptance solely to one school, thereby leaving admission vacancies to others.

4.6How to encourage the use of paperless admission?

Survey results in Figure 13 show that only 30\%, 16\% and $3 \%$ of A-Level private schools in KilimanjaroTanzania, respectively, use methods like postal office, phone calls, and electronic mail, these strategies still doesn't seem to be effective and economical to cut back the utilization of ink and paper admissions. Consequently, the rest of the school's admissions in A-Level private schools are performed manually, that in turns cost in terms of time and money. Additionally, such admission method is extremely slow, less accurate, difficult to complete likewise as effort consuming.

Therefore, in the new designed software solution TCPAS there'll be no need for applicants to collect physical forms for admission and fill it. Instead, all procedures for admission are going to be handled electronically through a web portal, and the system can automatize applicant's requests, answer all the desired query or requests, and eventually it will send notifications to applicants using mobile phone messages and electronic mail for all computers and mobile users. Thus, TCPAS meet the necessity of managing and controlling the paper to print admissions. Additionally, all admission reports are going to be provided in terms of PDF format, as shown in Figure 14.

\section{STUDENT PANEL [STUDENT PROFILE]}

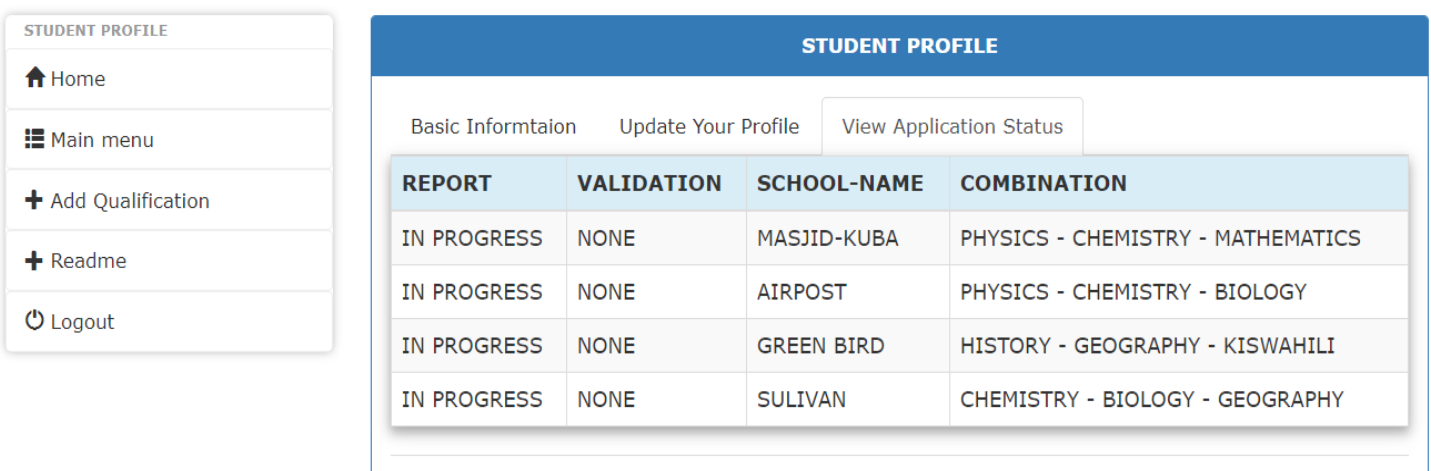

Figure 11 TCPAS response when an applicant performs multiple admissions 
STUDENT PANEL [STUDENT PROFILE]

\begin{tabular}{|c|c|c|c|c|c|}
\hline STUDENT PROFILE & \multicolumn{5}{|c|}{ STUDENT PROFILE } \\
\hline $\mathbf{n}$ Home & \multirow{2}{*}{\multicolumn{3}{|c|}{ Basic Informtaion Update Your Profile }} & \multirow{2}{*}{\multicolumn{2}{|c|}{ View Application Status }} \\
\hline IE Main menu & & & & & \\
\hline + Add Qualification & REPORT & VALIDATION & $\mathrm{SCHC}$ & OL-NAME & COMBINATION \\
\hline + Readme & SELECTED & ACCEPT & MASJ & ID-KUBA & PHYSICS - CHEMISTRY - MATHEMATICS \\
\hline \multirow[t]{3}{*}{ () Logout } & SELECTED & ACCEPT & AIRPC & & PHYSICS - CHEMISTRY - BIOLOGY \\
\hline & NOT SELECTED & WAIT & GREE & N BIRD & HISTORY - GEOGRAPHY - KISWAHILI \\
\hline & IN PROGRESS & NONE & SULIV & & CHEMISTRY - BIOLOGY - GEOGRAPHY \\
\hline
\end{tabular}

Figure 12 TCPAS response after schools accept or reject toward applicant requests

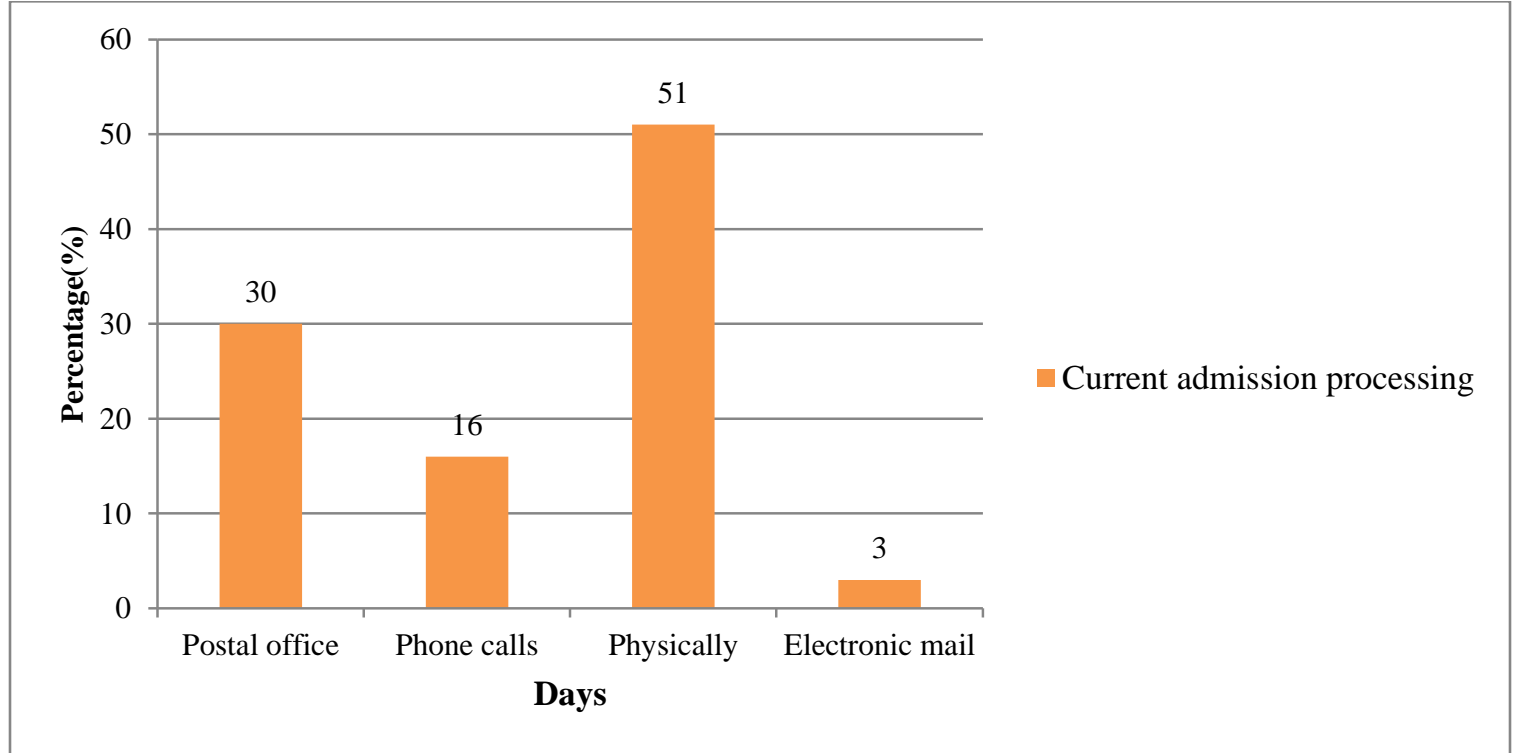

Figure 13 The current methods for admission processing in A-Level private schools in Tanzania

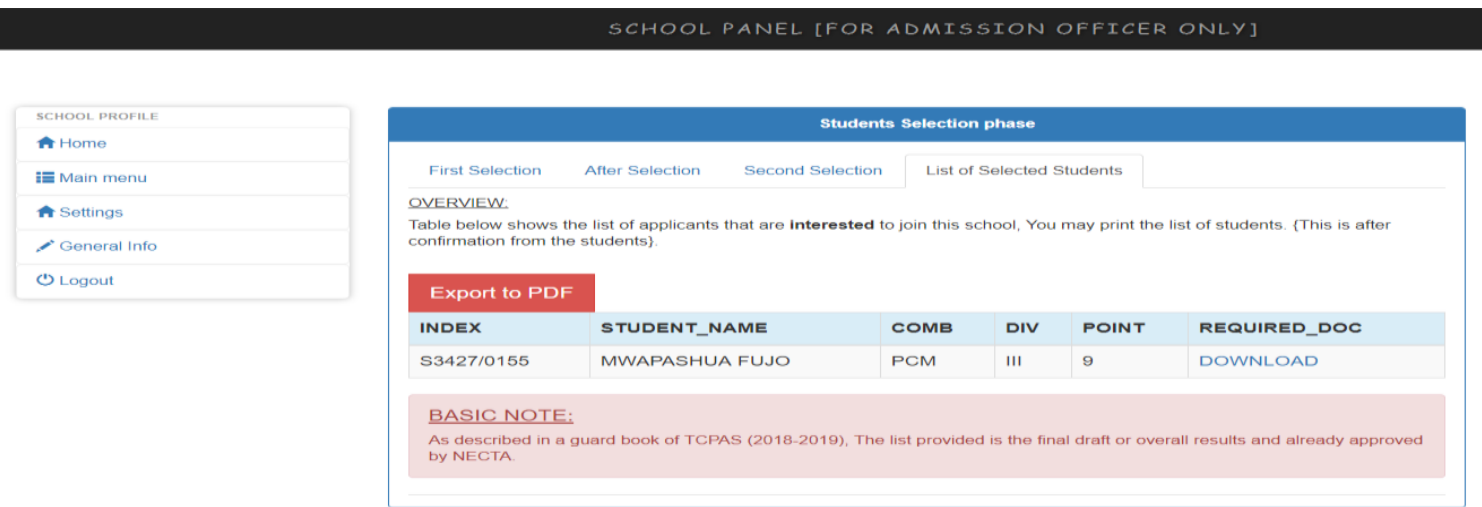

Figure 14 Interface for schools to generate reports showing the list of selected students

\section{Conclusion and recommendation}

The survey data from this study clearly confirm and quantify that many problems are still militating against the admission system into A-Level private schools in Tanzania. Despite of the contribution of private schools and the existence of these two 
systems (TCU and NACTE) in Tanzania, to date all the work at the time of admission in A-Level private schools are performed manually that is; on paper based, which is very slow and consuming much effort and time. Additionally, this manual system has its essential problems which include difficulty in locating an appropriate school and subjects an applicant can get admissions, wastage of time, and loss of forms and mutilation of forms throughout the whole process for admission. Therefore, this paper reports on an ongoing research work to design and implement a TCPAS that has the capabilities to deal with the admission challenges into A-Level private schools in Tanzania. This new system is going to solve the myriad of admission problems in the manual era. Thus, it is recommended that the government of Tanzania should construct a supportive policy which will promote and encourage all private schools, moreover public A-Level schools to deploy the TCPAS application tool, as a means of saving resources time and money, and enhancing performance of enrolment of students in A-Level schools in Tanzania.

\section{Acknowledgment}

None.

\section{Conflicts of interest}

The authors have no conflicts of interest to declare.

\section{References}

[1] Helms RM. University admission worldwide. World Bank; 2008.

[2] Ochwa-Echel JR. Private universities in Uganda: issues and challenges. International Journal of Education and Social Science. 2016; 3(3):7-18.

[3] Zhang H. Analysis of the Chinese college admission system. Edinburgh Research Archive. 2010.

[4] Mirji C, Deshpande V, Walunj S, Ambavane A. Eadmission system. IOSR Journal of Computer Engineering. 2014; 16(2):1-3.

[5] https://www.academia.edu/3410337/Challenges_of_St udents_Online_Registration_System. Accessed 27January 2018.

[6] Mahundu FG. E-governance: A sociological case study of the central admission system in Tanzania. The Electronic Journal of Information Systems in Developing Countries. 2016; 76(1):1-1.

[7] Mabu AM, Muhammed FA. An admission decision support system for Nigerian universities. International Journal of Computer Applications. 2016; 133(2):1-6.

[8] Emaikwu SO. Assessment of the impact of students' mode of admission into University and their academic achievement in Nigeria. International Journal of Academic Research in Progressive Education and Development. 2012; 1(3):151-64.
[9] Kanyip BP. Admission crisis in Nigerian universities: the challenges youth and parents face in seeking admission. 2013.

[10] http://tdsnfp.org/wpcontent/uploads/2013/06/Education-system-inTanzania-.pdf. Accessed 27 January 2018.

[11] https://www.jamiiforums.com/attachments/201314ad mission-pdf.95819/. Accessed 07 February 2018.

[12] Istoroyekti YM. Issues challenging universities: a case of Tanzanian higher education. Ahmad Dahlan Journal of English Studies. 2016; 3(1):51-62.

[13] http://planipolis.iiep.unesco.org/sites/planipolis/files/r essources/tanzania_sedp_2010_2015.pdf. Accessed 20 February 2018.

[14] Hare H. Survey of ICT and education in Africa: Tanzania country report.2007.

[15] NBS, OCGS. 2012 population and housing census: Population distribution by administrative units: Key findings.

[16] http://unohrlls.org/custom-content/uploads/2018/01/DLDC-ICTLDC-2018-PDF-E.pdf. Accessed 05 March 2018.

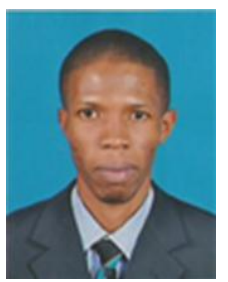

Mwapashua H. Fujo is a Master's Scholar, School of Information and Communication Science and Engineering, specialty in Information Technology Systems Development and Management. Obtained his B.Sc. degree in Information Technology from Stefano Moshi Memorial University College (SMMCo), a Constitute college of Tumaini University Makumira in 2016. His research interests include Information Systems Development, Multimedia Design, Graphics Design and Machine Learning (ML). He is passionate about teaching Programming Languages and Graphic Design.

Email: fujoprof@gmail.com

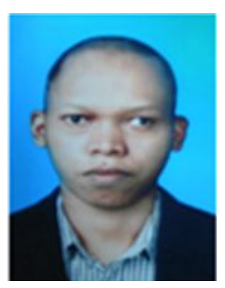

Mussa Ally Dida was born in 1983 in Dar-es-Salaam, Tanzania. He received his B.Sc. in Computer Engineering and Information Technology from University of Dar-es-Salaam (UDSM) and M.Sc. in Telecommunication Engineering from University of Dodoma (UDOM) both in Tanzania in 2008 and 2011 respectively, and a $\mathrm{PhD}$ in Information and Communication Engineering from Beijing Institute of Technology (BIT), Beijing, China in 2017. He is currently working as a Lecturer at Nelson Mandela African Institute of Science and Technology (NM-AIST) in Arusha, Tanzania and Academic Manager of the Centre of Excellence in ICT in East Africa (CENIT@EA) hosted by NM-AST. His research interest includes Digital Signal Processing, Fractional Fourier Transforms Signals and Systems, Physical Layer Security, and ICT4D. 